\title{
Correction to: FDA Approval of Angiotensin II for the Treatment of Hypotension in Adults with Distributive Shock
}

\author{
Fortunato Senatore ${ }^{1} \cdot$ Gowraganahalli Jagadeesh $^{1}$ (D) Martin Rose $^{1} \cdot$ Venkateswaran C. Pillai $^{2}$. \\ Sudharshan Hariharan ${ }^{2} \cdot$ Ququan Liu $^{3} \cdot$ Tzu-Yun McDowell $^{1}$ - Mohan K. Sapru ${ }^{4}$ Mary Ross Southworth ${ }^{1}$. \\ Norman Stockbridge ${ }^{1}$
}

Published online: 1 March 2019

(c) This is a U.S. government work and its text is not subject to copyright protection in the United States; however, its text may be subject to foreign copyright protection 2019

\section{Correction to: \\ American Journal of Cardiovascular Drugs \\ 2019;19(1):11-20 \\ https://doi.org/10.1007/s40256-018-0297-9}

The author name that previously read

McDowell Tzu-Yun

should read

Tzu-Yun McDowell.

The original article can be found online at https://doi.org/10.1007/ s40256-018-0297-9.

Gowraganahalli Jagadeesh

Gowra.Jagadeesh@fda.hhs.gov

1 Division of Cardiovascular and Renal Products, Center for Drug Evaluation and Research, Food and Drug Administration, 10903 New Hampshire Ave, Bldg 22, Room \#4128, Silver Spring, MD, USA

2 Office of Clinical Pharmacology, Center for Drug Evaluation and Research, Food and Drug Administration, Silver Spring, MD, USA

3 Office of Biostatistics, Center for Drug Evaluation and Research, Food and Drug Administration, Silver Spring, MD, USA

4 The Office of Pharmaceutical Quality, Center for Drug Evaluation and Research, Food and Drug Administration, Silver Spring, MD, USA 